\title{
TRITIUM STRIPPING BY A CATALYTIC EXCHANGE STRIPPER (U)
}

by

L. K. Heung', G. W. Gibson', and M. S. Ortman ${ }^{2}$

'Westinghouse Savannah River Company

Savannah River Site

Aiken, SC 29808

2142 Talatha Church Rd.

Aiken, SC 29808

An abstract of a paper proposed for presentation and publication at the

Fourth Topical Meeting on Tritium Technology

in Fission, Fusion, and Isotopic Applications

Albuquerque, New Mexico

September 29 - October 4, 1991

This paper was prepared in connection with work done under Contract No. DE-AC09.89SR 18035 with the U.S. Department of Energy. By acceptance of this paper, the publisher and/or recipient acknowledges the U.S. Government's right to retain a nonexclusive, royalty-free license in and to any copyright covering this paper along with the right to reproduce, and to authorize others to reproduce all or part of the copyrighted paper.

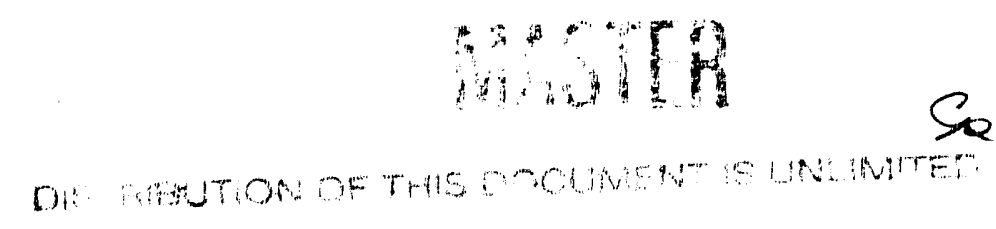


WSRC-MS-91-048

\title{
TRITIUM STRIPPING BY A CATALYTIC EXCHANGE STRIPPER (U)
}

by

L. K. Heung ${ }^{1}$, G. W. Gibson ${ }^{1}$, and M. S. Ortman ${ }^{2}$

' Westinghouse Savannah River Company

Savannah River Site

Aiken, SC 29808

${ }^{2} 142$ Talatha Church Rd.

Aiken, SC 29808

\begin{abstract}
A catalytic exchange process for stripping elemental tritium from gas streams has been demonstrated. The process uses a catalyzed isotopic exchange reaction between tritium in the gas phase and protium or deuterium in the solid phase on alumina. The reaction is catalyzed by platinum deposited on the alumina. The process has been tested with both tritium and deuterium. Decontamination factors (ration of inlet and outlet tritium concentrations) as high as 1000 have been achieved, depending on inlet concentration. The test results and some demonstrated applications are presented.
\end{abstract}

\section{INTRODUCTION}

Tritium processing facilities have been in operation at Savannah River Site since $1955 .^{\prime}$ In these facilities strippers are used to remove low levels of tritium in waste or purge gas streams before these streams are released to the environment. Conventional strippers make use of a multi-step process: (1) The gas stream is heated in a preheater. (2) The tritium is oxidized at high temperatures to tritium oxide in a catalyst bed. (3) The gas stream is cooled in a precooler. (4) The oxide is absorbed on a molecular sieve bed. (5) The tritium in the oxide is recovered by reduction using a high-temperature reduction bed. The tritiated water produced by this relatively complicated process is much more hazardous to personnel than is elemental tritium. Simpler and less hazardous tritium stripping processes are highly desired.

We have found that alumina containing a small amount of platinum as a catalyst can effectively remove elemental tritium from gas streams (such as air and helium) in a single step without producing tritiated water. The process uses a column packed with alumina pellets containing about 0.3 wt\% platinum. The gas stream containing tritium passes through the column at room temperature, and the tritium in the gas stream simply exchanges with the protium in the pellets. The result is the gas exiting the column contains protium instead of tritium. Upon saturation, the alumina column can be regenerated. The accumulated tritium can be recovered by a reverse ex- 
change process in which the column is backflushed with a small amount of protium. The resulting mixture of tritium and protium can then be separated by an isotope separation process.

The catalytic exchange process has been tested with both tritium and deuterium. Decontamination faciors (defined as the ratio of inlet and outlet tritium concentration) as high as 1000 have been achieved, depending on inlet concentration and the type of gas stream. Test results and demonstrated applications are presented.

\section{Principle of the Process}

The catalytic exchange process uses the catalyzed exchange reaction between tritium gas and the hydrogen or deuterium atoms in the solid aluminum oxide hydroxide $[\mathrm{AIO}(\mathrm{OH})]$ at room temperature: $[1]$

$$
\mathrm{T}_{2}+2 \mathrm{AIO}(\mathrm{OH})
$$

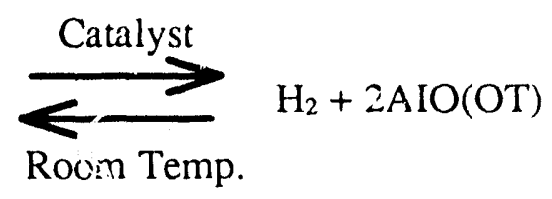

The reaction is reversible. During tritium stripping, the reaction proceeds to the right, and the tritium is retained in the solid alumina. To regenerate, the reaction is made to go to the left by adding $\mathrm{H}_{2}$. The net result is that the $\mathrm{T}_{2}$ is stripped from the air or other gas stream, and placed in a $\mathrm{H}_{2}$ stream. The $\mathrm{T}_{2}$ and $\mathrm{H}_{2}$ mixture can then be separated by an isotope separation process.

The advantages of the catalytical exchange stripper are that it operates at room temperature, and it does not convert the tritium to oxide. In comparison, the conventional stripper requires a high-temperature $\left(100-400^{\circ} \mathrm{C}\right.$ ) catalyst bed and converts the $\mathrm{T}_{2}$ to oxide. The oxide needs to be reduced to free the tritium (Figure 1 ).

\section{Experimental Equipment and Procedure}

Two sets of experimental equipment were used; one for $\mathrm{D}_{2}$ (cold) tests and the other for $\mathrm{T}_{2}$ (hot) tests. Cold tests using deuterium in the gas phase and protium in the solid phase focused on high concentrations of gas phase species $\left(1-100 \% \mathrm{D}_{2}\right)$. The cold tests were run on a variety of exchange materials including alumina coated with $\mathrm{Pt}$ and $\mathrm{Pd}$, molecular sieve coated with $\mathrm{Pt}$, and a commercial Englehard Deoxo $\mathrm{M}$ catalyst $(0.3 \% \mathrm{Pt}$ on alumina). In contrast, the hot tests focused on lower concentrations of gas phase tritium $\left(<1000 \mathrm{ppm} \mathrm{T}_{2}\right)$. These hot tests were run using the Deoxo $\mathrm{M}$ catalyst only.

For the cold tests (Figure 2), exchange materials to be studied were loaded into a $1.27 \mathrm{~cm}$ outside diameter stainless steel tube (inside diameter $=1.09 \mathrm{~cm}$ ). Two tube lengths were used, $61 \mathrm{~cm}$ and $15 \mathrm{~cm}$. The feed gas $\left(D_{2}\right.$ and $\mathrm{He}, \mathrm{D}_{2}$ and air, or pure $\left.\mathrm{D}_{2}\right)$ used in exchange column experiments was mixed in a 15 liter supply tank by addition of known pressures of the individual gas components to the tank. The mixtures were then sampled and analyzed by mass spectrometry to verify the final calculated compositions.

A flow controller located between the supply tank and the exchange column regulated the gas flow rate through the column. The gas exiting the column generally passed through a thermal conductivity detector, and was then vented to the atmosphere. The detector provided online 
analysis of the $D_{2}$ concentration exiting the column, though it was not sensitive to $D_{2}$ concentrations of $<1 \%$ in a gas stream. Therefore, periodic samples of the gas exiting the column were taken and analyzed by mass spectrometry. This extended the $\mathrm{D}_{2}$ sensitivity down to about 300 ppm.

A number of exchange materials coated with platinum were tested. The platinum coating solution was made by dissolving $2.6 \mathrm{~g}$ of $\mathrm{PtCl}_{4}$ in 1 liter of $1.2 \mathrm{M} \mathrm{HCl}$ solution. Coating was accomplished by saturating the exchange material with $\mathrm{PtCl}_{4}$ solution, drying the material, and then reducing the $\mathrm{PtCl}_{4}$ to $\mathrm{Pt}$ by flowing $\mathrm{H}_{2}$ over the heated material (about $200^{\circ} \mathrm{C}$ ). The water driven off the exchange materials in the high-temperature reduction step was replaced by flowing water saturated air over the coated materials. The quantity of platinum coated on the exchange material was determined by neutron activation analysis. Exchange materials coated with Pd were produced by the same method.

For the hot tests (Figure 3), the apparatus consisted of two U-shaped columns. Each column was fabricated from stainless steel tubing $3.175 \mathrm{~cm}$ in diameter, and had a volume of 1 liter. One column was filled with $0.32 \mathrm{~cm}$ alumina pellets coated with about $0.3 \% \mathrm{Pt}$ (Engelhard Deoxo $0^{\oplus}$ ) to serve as the catalytic exchange column. The other column was filled with zeolite type $4 \mathrm{~A}$ and was installed ahead of the exchange column. The zeolite column was used to reduce the moisture level in the air stream, and could be bypassed when removal of moisture was not required.

With the 3.175-cm-diameter exchange column the residence time was limited to one minute or longer by the gas flow rate available. A second, smaller column made out of tubing 1.91 $\mathrm{cm}$ in diameter with a volume of 0.25 liter was used for tests with residence times less than one minute.

Room air and cylinder nitrogen were used as the carrier gases. The gas was drawn though the columns by a yacuum pump at the outlet end of the columns. The flow rate was controlled by a needle valve, and measured by a rotameter. The concentration of tritium was controlled by bleeding tritium and argon mixtures through calibrated leaks into the carrier gas stream. Tritium concentrations of about 0.001 to $1000 \mathrm{ppm}$ were tested.

The duration of each test was set arbitrarily, and could be anywhere between 45 minutes and seven hours, because it was shown that the exit concentration reached steady state in less than two residence times. No regeneration was required between tests since that column was far from being saturated.

Low-level tritium concentrations were measured using a triton portable tritium monitor for online readings. Higher level tritium concentrations are measured by taking samples at the appropriate point, expanding the sample into an ionization chamber, and measuring the ion current with a vibrating reed electrometer.

The hot test column was also used for application demonstrations. 


\section{RESULTS AND DISCUSSION}

\section{Breakthrough Curve and Decontamination Factor (DF)}

When the feed gas containing $\mathrm{D}_{2}$ (or $\mathrm{T}_{2}$ ) enters the column and the $\mathrm{D}$ atoms exchange with the $\mathrm{H}$ atoms in the solid phase, an S-shape concentration profile is developed. This profile moves toward the end of the column and eventually exits the column completely. The breakthrough curve is the $D_{2}$ concentration rneasured at the exit of the column against time (or amount of effluent). See Figure 4. Usually the concentration of $D_{2}$ stays near zero for a long period of time, and then rapidly increases to the same concentration as the feed. The length of time it stays near zero and the actual shape of the curve depends on the type of exchange material, flow rate (residence time), and otiner factors. The amount of $\mathrm{D}$ or $\mathrm{T}$ exchanged before the concentration begins to rise defines the exchange capacity of a material. The performance of an exchange column is measured by a decontamination factor (DF) defined as the feed concentration divided by the exit concentration.

\section{Pretreatment of Exchange Material}

Pretreatment affects both the capacity and kinetics of the exchange material. The exchange reaction relies on the $\mathrm{H}$ atoms in the solid phase, and the effect of the catalyst ( $\mathrm{Pt}$ or $\mathrm{Pd})$. The amount of $\mathrm{H}$ atoms available affects the exchange capacity of the material. Tests showed that an alumina sample can have a capacity of 40 to 200 standard temperature and pressure cubic centimeters per gram (STPcc/g) depending on how the sample is prepared (see later section). Exposing a new column to moist air before use can assure its capacity, but does little to the kinetics. Exposure of the new material to a high concentration of hydrogen for one hour or more is necessary to bring up the kinetics. Tes ts showed that without the first hydrogen exposure, the DF of a new column is only about six. After the hydrogen exposure the DF increases to the normal level about 300 and higher (Table 1). The hydrogen exposure may have removed undesired impurities from the catalyst surface, which improved the kinetics.

\section{Capacity}

The capacity of an exchange material is strongly affected by the amount of catalyst and how uniformly it is distributed in the pellets. The $\mathrm{H}$ atoms that are not close to the catalyst surface are not available for the exchange reaction because of the lack of kinetics. The Deoxo ${ }^{\oplus} \mathrm{M}$ contains about $0.3 \% \mathrm{Pt}$, but the $\mathrm{Pt}$ is in a small region near the outside of the pellet amounting to about one-fifth of the total volume of the pellet. The average measured exchange capacity of Deoxo ${ }^{\boxplus} \mathrm{M}$ was only $50 \mathrm{STPcc} / \mathrm{g}$, about one-fifth of the calculated capacity of $255 \mathrm{STPc} / \mathrm{g}$ of the $\mathrm{AIO}(\mathrm{OH})$. Redistribution of the $\mathrm{Pt}$ in Deoxo $0^{\circledast} \mathrm{M}$ pellets by the coating procedure described earlier increased the capacity to $140 \mathrm{STPcc} / \mathrm{g}, 55 \%$ of the calculated capacity. A sample thoroughly coated with $4 \%$ Pd achieved a capacity of 200 STPcc/g, $78 \%$ of the calculated value.

\section{Regeneration}

Regeneration of the $\mathrm{Pt}$ and alumina column can be readily accomplished by backflushing the column with $\mathrm{H}_{2}$ at room temperature (See Figure 4). Since the formation of $\mathrm{AIO}(\mathrm{OH})$ is not thermodynamically favored compared with $\mathrm{AIO}(\mathrm{OD})$ or $\mathrm{AIO}(\mathrm{OT})$, regeneration is less efficient compared to the stripping step. But the deficiency is overcome by using high-concentration $\mathrm{H}_{2}$ and increasing the residence time. Tests demonstrated that the integrated concentration of $\mathrm{D}_{2}$ in the $\mathrm{H}_{2}$ regeneration gas after $90 \%$ regeneration of original capacity was $15 \%$; the integrated con- 
centration after complete $(>99.9 \%$ ) regeneration was $6.7 \%$. In general, these concentrations are well above the original corcentration in the waste gas of $<1 \%$. The stripper not only can strip the tritium, but also can concentrate the stream.

\section{Effect of Catalyst Type on Kinetics}

Alumina pellets coated with either Pt or Pd were tested for their kinetics. Pt is a better catalyst than $\mathrm{Pd}$. At a residence time on one minute, the $\mathrm{Pt}$ and alumina sample achieved about $60 \%$ of its total exchange capacity before the concentration began to break through. In comparison, the Pd and alumina sample achieved only about $20 \%$ of its total capacity before break through occurred. These results are not surprising in view of the comparative catalytic efficiencies of $\mathrm{Pd}$ and $\mathrm{Pt}$ for the exchange reaction between $\mathrm{H}_{2}$ gas and $\mathrm{HDO}$ vapor. $\mathrm{Pt}$ has been found to have an activity significantly higher than $\mathrm{Pd}^{.2,3]}$

A molecular sieve sample (Davison Chemical 8-12 mesh 5A) coated with Pt was tested for comparison, with a feed composition of $10 \% \mathrm{D}_{2}$, and $90 \% \mathrm{He}$. At residence times longer than about one minute, the DF of the molecular sieve sample was about the same as that of a Deoxo M sample. But when the residence time was decreased to less than one minute, the DF of the molecular sample decreased rapidly, while that of the Deoxo $0^{\infty} \mathrm{M}$ sample remained high. $\mathrm{Pt}$ and alumina is a better exchange material than the Pt and molecular sieve.

\section{Effect of Carrier Gas, Feed Concentration and Residence Time}

Hot tests were conducted with three carrier gases: dried air (after a ziolite bed), room air ( $1.3 \mathrm{~mol}_{\mathrm{H}} \mathrm{H}_{2} \mathrm{O}$ ), and nitrogen. Results showed that $\mathrm{Pt}$ and alumina is effective in stripping $\mathrm{T}_{2}$ from all three carrier gases with slight differences. The results are plotted in Figure 5 in terms of DF versus feed concentration with residence time as the other variable. In general, the DF is a strong function of feed concentration.

With dried air as the carrier gas, tests were conducted with feed concentrations varying from $5 \times 10^{3}$ to $1.3 \times 10^{9}$ microcuries per cubed meter $\left(\mu \mathrm{Ci} / \mathrm{m}^{3}\right)$ tritium $(0.002 \mathrm{ppm}$ to $500 \mathrm{ppm}$ tritium). DF values from 1 to 600 were obtained depending on the feed concentration. "The difference in DF between one minute residence time and 10 minute residence time is insignificant indicating the kinetics are not the controlling factor when the residence time is one minute or longer. But when the residence time is decreased to 15 seconds, the DF decreases from about 100 to 15 at the feed concentration of $10^{8} \mu \mathrm{Ci} / \mathrm{m}^{3}$ indicating the kinetics become the limiting factor. The dependence of DF on feed concentration (F) when dried air is the carrier gas may be approximated by the following equation:

$$
D F=0.00076 F^{0.65} \quad\left(\text { for } F>6.3 \times 10^{4} \mu \mathrm{Ci} / \mathrm{m}^{3}\right)
$$

Moisture in the carrier gas was found to have an effect on the DF. A test conducted with the zeolite bed, bypassed so that the moisture at about $1.3 \%$ was not removed from the air, gave a DF of 22 compared to 115 when the zeolite bed is in line. When moisture is in the gas phase, some exchange between $\mathrm{H}$ and $\mathrm{T}$ to form HTO might have taken place. The presence of HTO in the exit gas could have caused the decrease in DF. In application of the catalytic stripper, a zeolite bed should be placed upstream to remove the moisture from the gas.

With nitrogen gas as the carrier the results are similar to that of air, but at the same feed concentration the DF of a nitrogen case is slightly higher than that of an air case. The DF also 
remained the same even when the residence time decreased from 10 minutes to 15 seconds. These results indicate that the kinetics are faster with nitrogen gas as the carrier gas than with air. This difference might be caused by the presence of oxygen, but more understanding is required. With faster kinetics, a lower concentration of tritium in the outlet stream may be achieved with nitrogen, and probably other inert gases as the carrier gas. The dependence of DF on feed concentration for the nitrogen cases is approximated by:

$$
\mathrm{DF}=0.0033 \mathrm{~F}^{0.59} \quad\left(\text { for } \mathrm{F}>1.6 \times 10^{4} \mu \mathrm{Ci} / \mathrm{m}^{3}\right)
$$

\section{Example of Demonstrated Applications}

\section{Unloading Tritium From Test Containers}

More than 30 test containers, each containing from 30 to $100 \mathrm{Ci}$ of tritium were unloaded through the exchange stripper. Recovery of the tritium was $99.9 \%$ or better. The unloading was accomplished by placing the test container in a containment bag. After the bag had been purged with nitrogen, the fill tube of the container was cut allowing the contents to expand into the containment bag. A flow of nitrogen circulating through the bag and the stripper swept the tritium into the stripper where the tritium was exchanged for protium. The bag volume was 25 liters and the nitrogen flow rate was one standard temperature and pressure liter per minute (STPL/ $\mathrm{min}$ ) for one minute residence time in the stripper. Each run lasted about two hours and recovered $99.9 \%$ or better of the tritium in the test container.

\section{Off-gassing of Reservoirs and Test Samples}

When reservoirs containing tritium are unloaded, they are stored in a ventilated cabinet where they are allowed to off-gas until the rate is low enough to permit further handling. This off-gassing accounts for about $5 \%$ of the normal routine tritium emissions from one of the facilities at the Savannah River Site.

A test was designed to demonstrate the capability of the exchange stripper to reduce tritium emissions from this source. Six newly unloaded reservoirs were placed into a container. The container was connected to the stripper so that a nitrogen stream at $1 \mathrm{STPL} / \mathrm{min}$ could be recirculated through the container and the stripper. Samples taken after three hours of operation showed that the feed and exit concentrations were $5.6 \times 10^{7}$ and $3.3 \times 10^{5} \mu \mathrm{Ci} / \mathrm{m}^{3}$, respectively, which gave a DF of 170 for each pass. The operation continued for two weeks, and recovered more than $99 \%$ of the off-gas tritium. This test demonstrated that a catalytic exchange stripper may be used to reduce tritium loss from this source.

\section{CONCLUSIONS}

A catalytic exchange stripper using Pt-deposited alumina has been demonstrated as a simple and practical process to remove tritium from either air or inert gas streams at room temperature. The stripper has a high capacity, produces no tritiated water, and is easily regenerated. The small size and low power requirements of this process permit it to be installed easily, or be designed to be portable. It is expected to have wide applica ons in the reduction of tritium releases to the environment.

More studies are required to further understand the kinetics, equilibrium and separation factor of the exchange reaction, and their dependence on temperature. The results of this study 
showed that the effectiveness of the catalytic stripper is limited to tritium concentrations of $10^{4}$ $\mu \mathrm{Ci} / \mathrm{m}^{3}$ (or $10^{-2} \mu \mathrm{Ci} / \mathrm{cc}$ ) or higher. This limit should be studied and improved.

\section{ACKNOWLEDGEMENT}

The authors wish to thank H. D. Brown, F. Key and G. Williams for their help in conducting the experiments. The information in this article was developed during the course of work under Contract No. DE-AC09-89SR18035 with the U.S. Department of Energy.

\section{REFERENCES}

1. M. S. Ortman, L. K. Heung, A. Nobile, and R. L. Rabun III, "Tritium Processing at the Savannah River Site: Present and Future", J. Vac. Sci. Technol. A 8 (3) 2881, May/June 1990.

2. N.H. Sagert and R. M.L. Pouteau "Hydrogen-Water Deuterium Exchange over Graphite Supported Group VIII Noble Metals", Can. J. Chem. 51, 4031, 1973.

3. N. H. Sagert and R. M. L. Pouteau "Hydrogen-Water Deuterium Exchange over Unsupported Group VIII Noble Metals", Can. J. Chem. 52, 2960, 1974. 


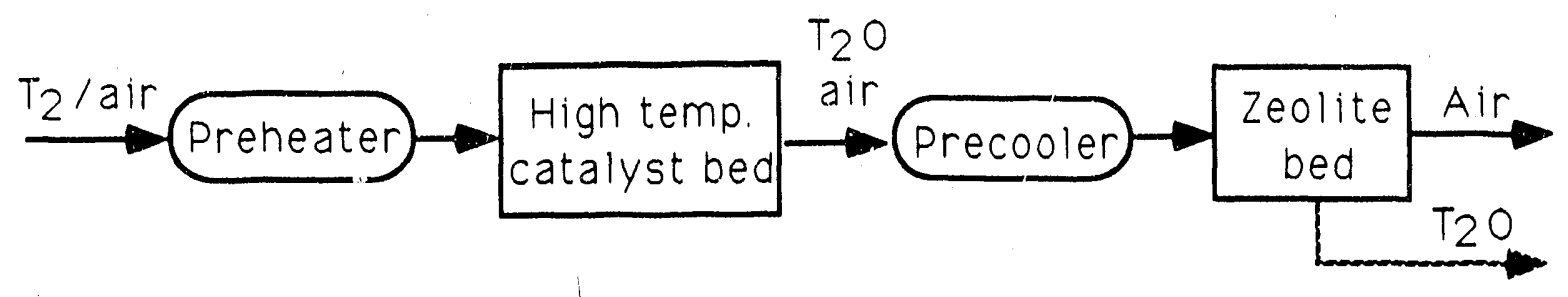

Catalytic exchange stripoer

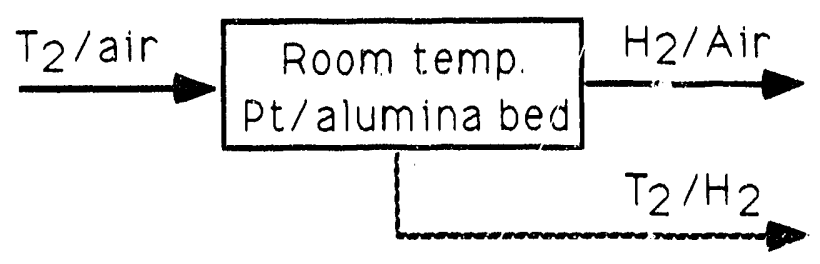

Fig. 1 Conventional Stripper vs. Catalytic Exchange Stripper 


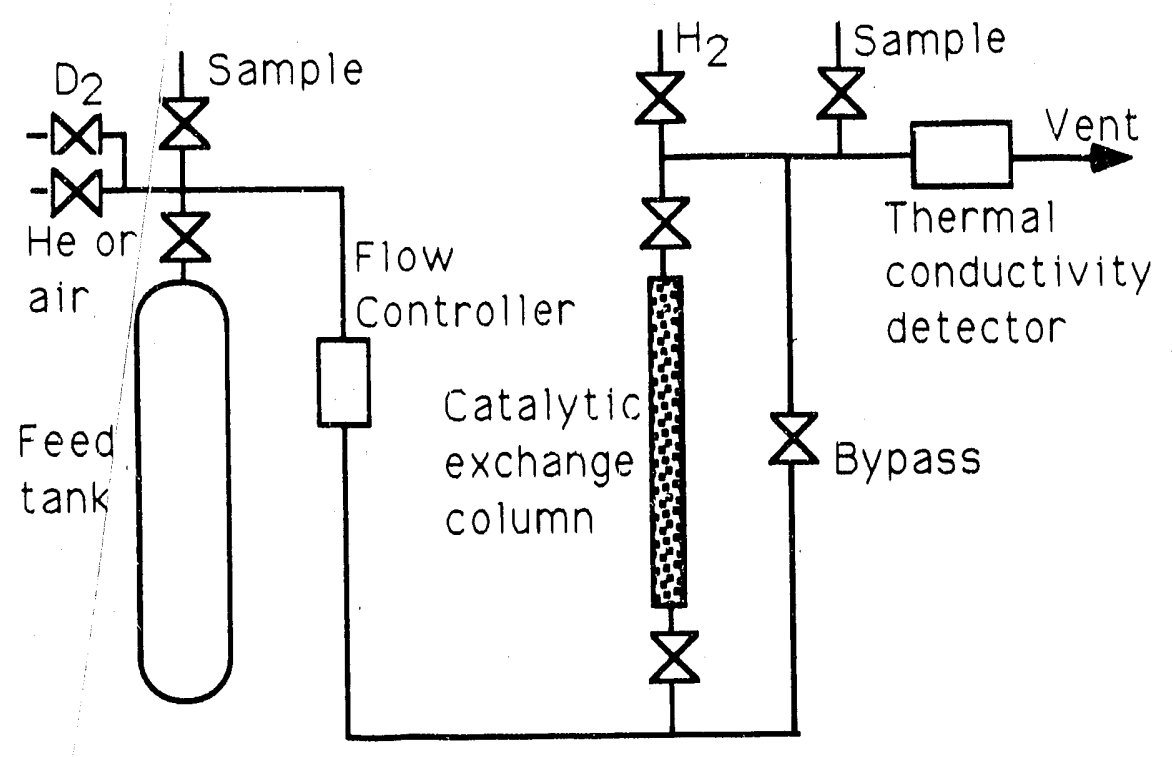

Fig. 2 Schematic of the Catalytic Exchange Stripper for $\mathbf{D}_{\mathbf{2}}$ (Cold) Tests 


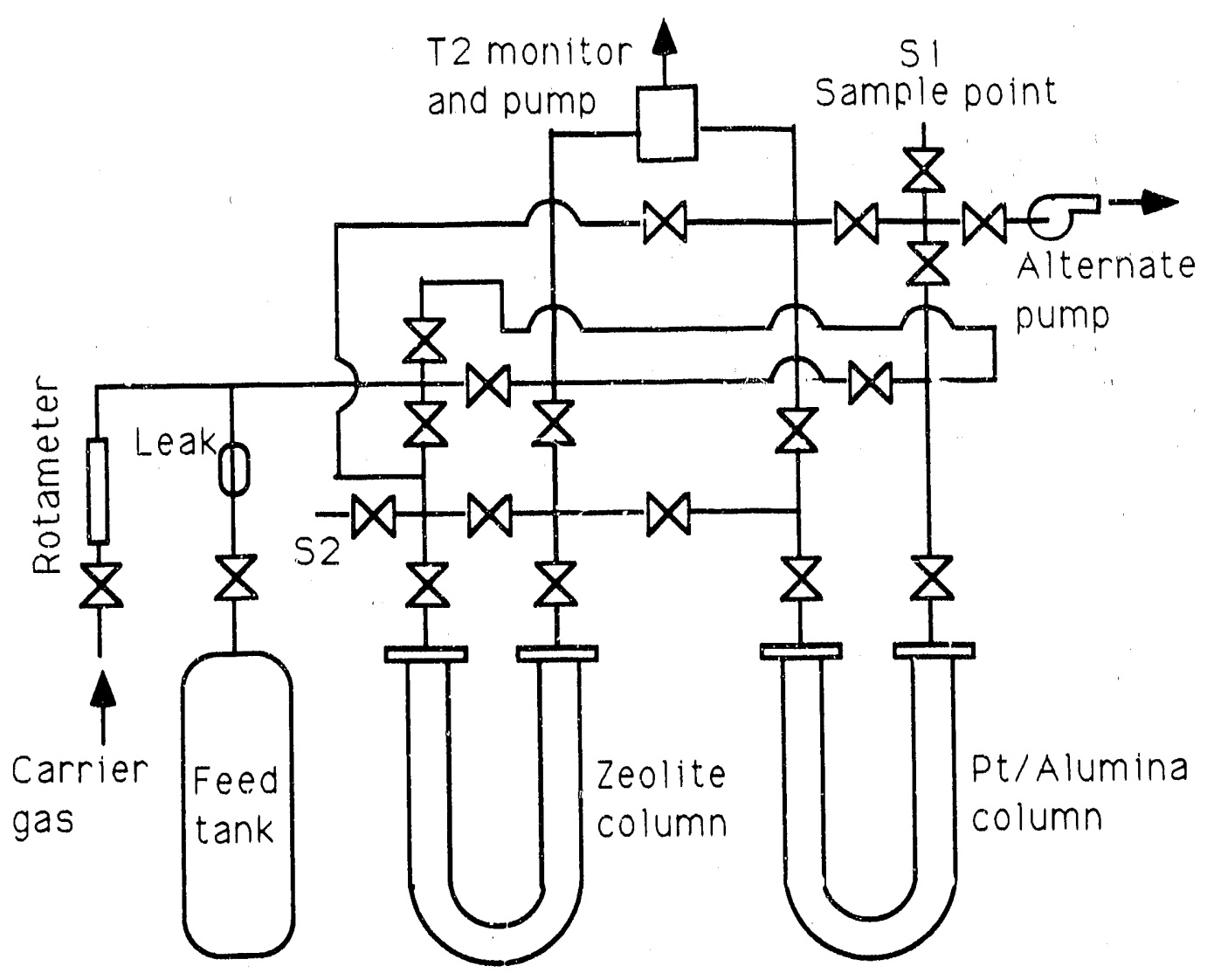

Fig. 3 Schematic of the Catalytic Exchange Stripper for $T_{2}$ Tests 


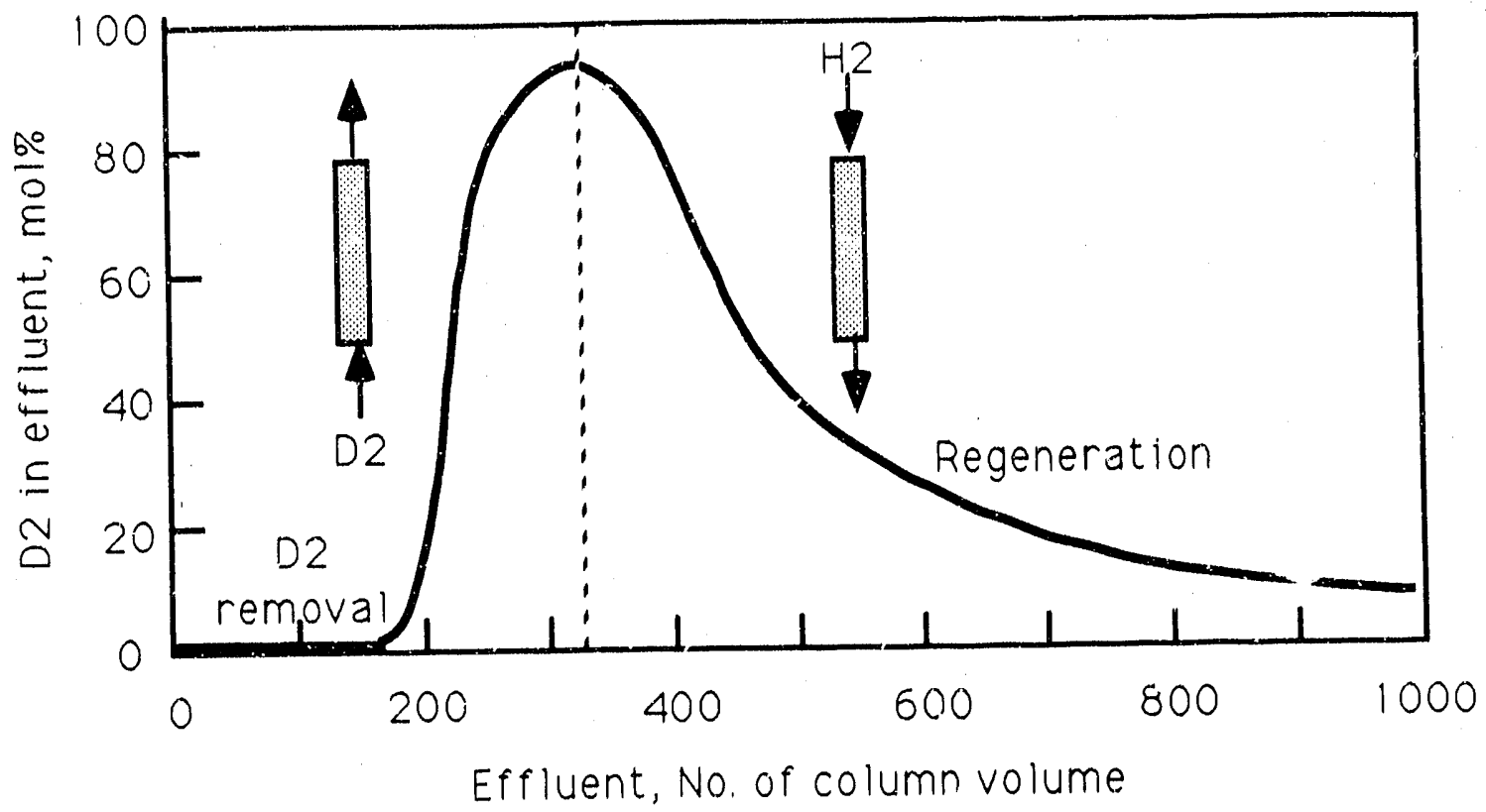

Fig. 4 Breakthrough Curve and Regeneration of the Catalytic Exchange Stripper 


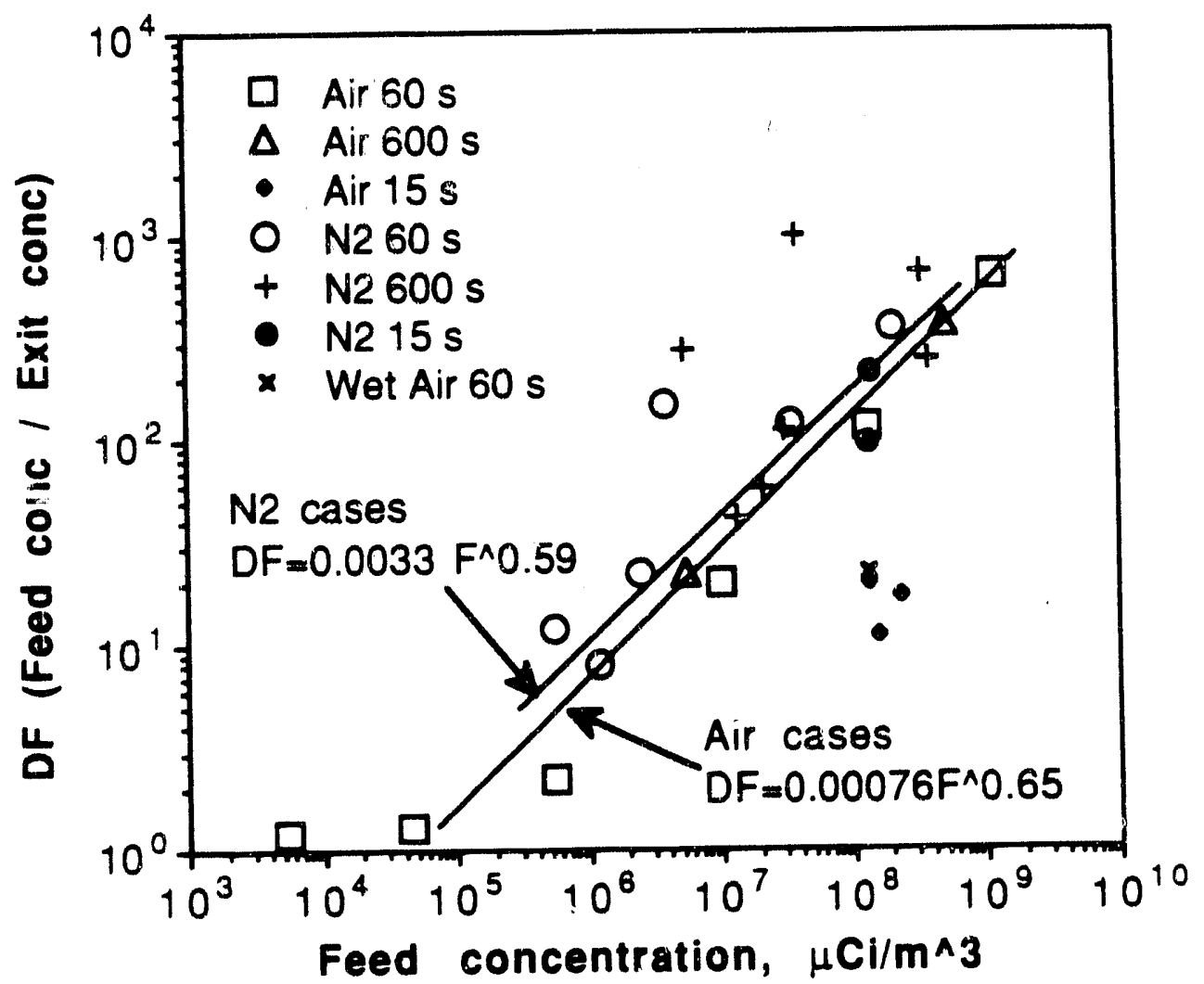

Fig. 5 Data of Tritium Decontamination Factor 


\begin{tabular}{|cccc|}
\hline $\begin{array}{c}\text { Exposure } \\
\text { to } \mathrm{H} 2\end{array}$ & $\begin{array}{c}\text { Exposure to } \\
\text { moisture } \\
\text { (hour) }\end{array}$ & $\begin{array}{c}\text { Residence } \\
\text { time } \\
\text { (second) }\end{array}$ & $\begin{array}{c}\text { Average } \\
\mathrm{DF} \\
(\mathrm{T} 2 \text { in/out) }\end{array}$ \\
0 & 0 & 60 & 6 \\
1 & 168 & 60 & 6 \\
1 & 0 & 60 & 340 \\
1 & 0 & 20 & 290 \\
1 & 8 & 60 & 730 \\
\hline
\end{tabular}

Table 1. Pretreatment Effect on Deoxo ${ }^{\circledR}$ M Material 

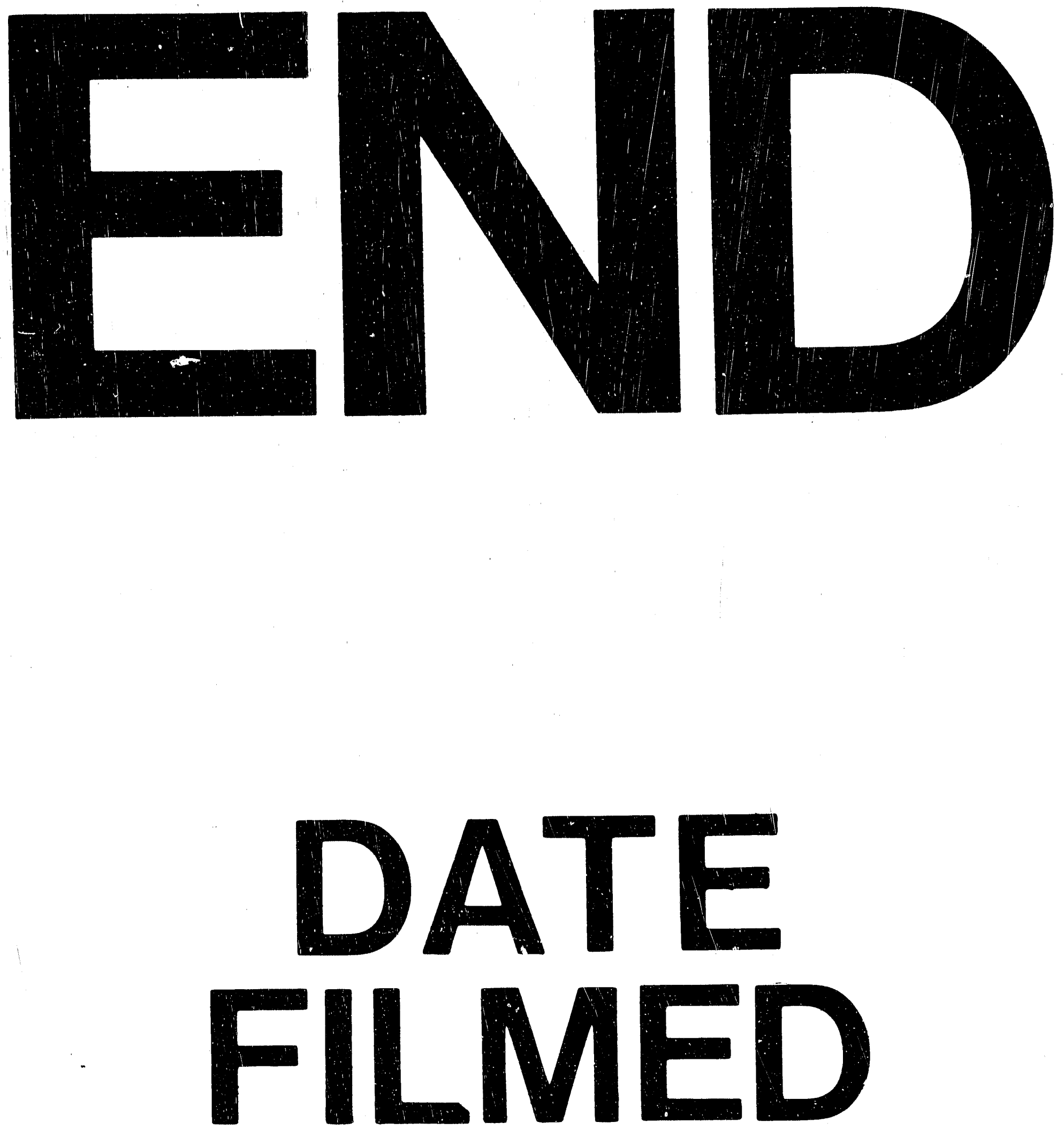

F

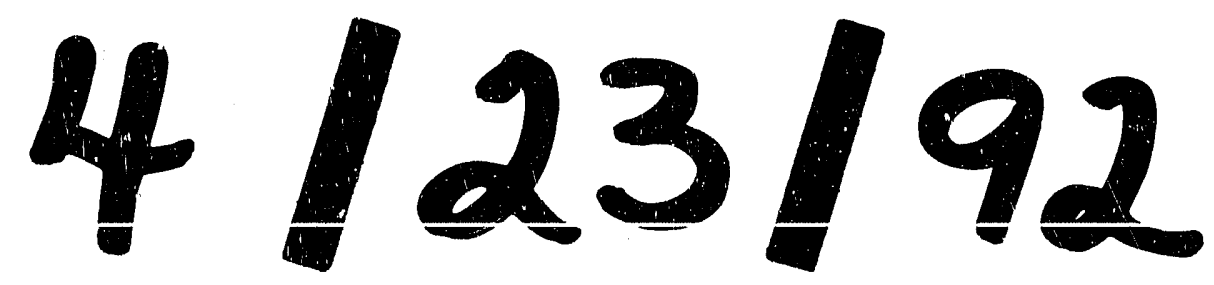


